\title{
РАЗВИТИЕ МОНОГОРОДОВ В УСЛОВИЯХ МОДЕРНИЗАЦИИ ЭКОНОМИКИ
}

\author{
О.Д. УГОЛЬНИКОВА \\ к.ф-м.н., доц. СПбГУСЭ \\ РИЗОВ А.Д. \\ аспирант СПбГУСЭ
}

\section{Аннотация:}

Развитие моногородов в условиях модернизации экономики России является важнейшим аспектом не только развития экономики страны, но и основой социальной стабильности в обществе и фактором регулирования внутренних миграционных потоков.

В статье рассматриваются различия экономического развития регионов, с учетом разных природных условия, обеспеченности инфраструктурой и ресурсами, дана классификация моногородов и сделан сравнительный анализ экономического развития регионов России.

Также в статье рассмотрены варианты стратегического развития регионов и моногородов с учетом трендов мировой экономики.

Ключевые слова: моногород, экономика, модернизация

\section{ВВЕДЕНИЕ}

Моногорода являются острым, но малоизученным фактом российской экономики. Моногорода получили широкое распространение на территории РФ и развивались по принципу «предприятие - город», для включения в экономический оборот природных ресурсов и обустройства территории. Предприятия таких городов получили статус градообразующих, обеспечивая на рынке труда спрос на труд, строительство, коммунальные услуги, связь, транспорт его жителям. При переходе к рынку проблемы этих городов привели к необходимости выработки специальных подходов по устойчивому развитию экономики, а в период кризиса 2008-2009 гг. - к необходимости выработки специальных программ государственной поддержки.

\section{РЕЗУЛЬТАТЫ И ИХ ОБСУЖДЕНИЕ}

С учетом разнообразий по численности, уровню жизни, отраслевой принадлежности, развитию территорий и инфраструктуры моногорода во многом отличаются друг от друга. Общим является неконкурентоспособность градообразующих предприятий. При этом экономика моногородов зависит от экспорта их товаров и резко меняющейся конъюнктуры не только мировых, но и российских цен на их продукцию.

Моногорода, оказавшиеся в особо трудной экономической ситуации, претендовавшие и получившие финансовую поддержку из федерального бюджета 
в 2010 году: Чусовой (Пермский край), Асбест (Свердловская область), Карабаш (Челябинская область), Дальнегорск (Приморский край), а также не включенные в список из 27 моногородов: Белорецк (Башкортостан), Новотроицк (Оренбургская область), Аша, Сатка, Бакал, Златоуст, Магнитогорск (Челябинская область), Первоуральск, Нижний Тагил (Свердловская область) и другие связаны с металлургической отраслью в соответствии с профилем градообразующего предприятия.

Российская металлургическая промышленность на международном рынке по производству стальных труб, экспорту металлопродукции, алюминия, никеля, титанового проката занимает достаточно высокое место, а тенденции развития отрасли оцениваются как положительные [1]. Приведем статистику. В 2010 году был зафиксировано ускорение темпов отрасли. Индекс металлургического производства и производства готовых металлических изделий по сравнению с 2009 г. составил 114,6\%, в том числе по продукции металлургического производства $-115,6 \%[1]^{2}$. В период после финансово-экономического кризиса важнейшими для отрасли стали мероприятия на следующих предприятиях:

- Магнитогорском металлургическом комбинате - ввод в эксплуатацию комплекса по производству толстолистового железа,

- Новолипецком металлургическом комбинате - введение в строй четвертого агрегата непрерывного горячего цинкования,

- Волжском трубном заводе - запуск трубоэлектросварочного стана,

- Таганрогском металлургическом заводе - установка непрерывного трубопрокатного стана трехвалковой прокатки,

- Челябинском трубопрокатном заводе - запуск финишного цеха по выпуску антикоррозийных обсадных и насосно-компрессорных труб.

В 2011 г. выросло потребление труб основными потребителями - предприятиями нефтегазодобывающей промышленности, машиностроения и строительной индустрии, производство сплавов на основе первичного алюминия в январе-июне 2011 г. составило 137,4\% к соответствующему периоду предыдущего года. В первом полугодии 2011 г. по металлургическому производству и производству готовых металлических изделий среднесписочная численность работников по полному кругу организаций увеличилась на 26 тыс. чел., составив 985,3 тыс. чел., 102,7\% к соответствующему периоду 2010 г. Среднемесячная заработная плата работников увеличилась и составила 22719,4 руб., 115,6\% к 2010 г. (19651,7 руб.) [2]

Принимая во внимание перечисленные достижения, следует отметить несоответствие технико-технологического уровня отрасли в целом требованиям конкурентоспособности на мировом рынке [2] Это в наибольшей мере относится к большинству предприятий российских моногородов металлургического профиля.

Применив классификацию моногородов по принадлежности к компаниям крупного бизнеса металлургической и нефтедобывающей отрасли, отметим, что наибольшее их количество расположено в Свердловской области и Пермском крае (Приволжском ФО и Уральском ФО, соответственно). Стратегии развития 
российских регионов на современном этапе связываются с инновациями в промышленности, технологиях, управлении, сервисе. По соотношению уровня инновационной активности и инновационного потенциала российские регионы условно разделены на четыре типа инновационного климата. Пермский край и Свердловская область, наряду с Республикой Татарстан, Москвой, СанктПетербургом, и Московской областью отнесены к регионам с благоприятным типом инновационного климата. Другими типами инновационного климата являются консервативный, нейтральный и нестабильный [3].

Среди регионов с благоприятным типом климата Пермский край и Свердловская область находятся в группе технологических лидеров вслед за Республикой Татарстан. В соответствии с паспортом инновационной активности Пермского края [4] $]^{6}$, его лидирующее положение связано с хорошо развитой инновационной структурой и высоким уровнем инновационной активности. Действительно, инфраструктура генерации знаний включает четыре крупных научно-исследовательских центра, одиннадцать высших учебных заведений, при этом численность студентов на 10 тыс. населения составляет 389 человек. В инфраструктуру разработки и внедрений инноваций входит технопарк «Сосновый бор», четыре крупных и целая сеть мелких бизнес-инкубаторов, расположенных в районных центрах края, центр трансферта технологий. Территория инновационного развития представлена наукоградом «Звездный». Ресурсы для инновационной деятельности обеспечены 0,73\% персонала, занятого научными исследованиями и разработками, и на 10 тысяч населения края приходится 1,8 кандидатов наук и 0,4 докторов наук. Доля внутренних затрат на научные исследования и разработки составила 1\% от ВРП, а доля затрат на технологические инновации - 2,07\% от ВРП. Инновационная активность Пермского края связана с деятельностью 102 инновационных предприятий и фирм. Доля организаций, осуществляющих технологические инновации, составляет 26,4\% от общего числа организаций. Объем инновационных товаров, работ и услуг10,8\% от их общего объема. По числу созданных передовых производственных технологий и числу патентных заявок на одну тысячу исследований показатели по Пермскому краю превышают аналогичные показатели в целом по РФ: 15 и 112 (10 и 111) соответственно. Наконец, доля экспорта технологий и услуг технического характера составляет 1,63\% от общего объема экспорта. Для сравнения, инновационный лидер - Санкт-Петербург и технологический лидер Свердловская область представлены следующими числовыми значениями по перечисленным показателям, соответственно:

- 63 и 20 государственных вузов,

- 55 и 25 научно-исследовательских центров,

- 6 и 11 технопарков,

- 5 и 7 крупных бизнес-инкубаторов,

- 22 и 6 инновационно-технологических центров и центров трансферта технеологий,

- 1 и 4 наукограда,

- 5 и 2 программы (стратегии) инновационного развития, 
- 3,3 и 1,2 - доля персонала занятого исследованиями и разработками,

- 19,8/ 6,4 и 3,8/1,2 - кандидатов/ докторов наук на 10 тысяч населения,

- 3,43 и 1,18 - доля внутренних затрат на научные исследования и разработки, в \% от ВРП,

- 0,84 и 3,06 - доля затрат на технологические инновации, в \% от ВРП,

- 523 и 12 - инновационные предприятия и фирмы,

- 12,5 и 13,3 - доля организаций, осуществляющих технологические инновации, в \% от общего числа,

- 2,8 и 7,0 - объем инновационных товаров и услуг, в \% от общего объема,

- 89 и 27 - число созданных передовых производственных технологий,

- 42 и 75 - число патентных заявок на 1000 исследователей,

- 0,77 и 0,12 - доля экспорта технологий и услуг технического характера, в $\%$ от общего объема ${ }^{7}$.

При проведении сравнения установлено, что по таким показателям как число крупных технопарков, наукоградов, доля внутренних затрат на научные исследования и разработки и на технологические инновации Пермский край, Санкт-Петербург и Свердловская область имеют сравнимые показатели. Что касается инновационной активности, то по количеству инновационных предприятий и фирм Пермский край более чем в восемь раз превышает аналогичный показатель по Свердловской области. По показателю «доля организаций, осуществляющих технологические инновации» Пермский край более чем в два раза превышает аналогичный показатель г. Санкт-Петербург и в два раза Свердловской области, а показатель «объем инновационных товаров и услуг» (в 4 и 1,5 раза, соответственно). Если по числу созданных передовых производственных технологий пермский край уступает и Санкт-Петербургу и Свердловской области в 6 и 1,8 раза соответственно, при этом превышая общероссийский показатель в 1,5 раза, то по числу патентных заявок на одну тысячу исследователей в Пермском крае их подано в 2,7 и в 1,5 раза больше, чем в г. СанктПетербург и Свердловская область соответственно. Наконец, доля экспорта технологий и услуг технического характера в Пермском крае превышает аналогичный показатель в г. Санкт-Петербург в 2,1 раза, а в Свердловской области в 13,6 раз. Эти регионы с благоприятным типом инновационного климата формируют и транслируют собственный опыт. Лидерство Пермского края по целому ряду показателей инновационного потенциала и уровня инновационной активности играет существенную роль в формировании численных значений показателей (инфраструктура генерации знаний, «информационноконсалтинговая инфраструктура», производственно-технологическая инфраструктура, финансовая инфраструктура) при проведении оценки инновационной инфраструктуры Приволжского ФО.

Сравним численные значения указанных показателей в Приволжском и Уральском Федеральном округе. Учитываем, что и Свердловская область, входящая в УрФО, также как и Пермский край, участвует в их формировании (Таблица 1). 
Таблица 1 - Структура инновационной инфраструктуры федеральных округов: сравнительная характеристика Приволжского ФО и Уральского ФО

\begin{tabular}{|l|l|c|c|}
\hline \multicolumn{1}{|c|}{$\begin{array}{c}\text { №o } \\
\text { п/п }\end{array}$} & \multicolumn{1}{|c|}{ Показатель } & Приволжский ФО (\%) & уральский ФО (\%) \\
\hline 1 & $\begin{array}{l}\text { Инфраструктура генерации зна- } \\
\text { ний }\end{array}$ & 38 & 40 \\
\hline 2 & $\begin{array}{l}\text { Информационно-консалтинговая } \\
\text { инфраструктура }\end{array}$ & 20 & 15 \\
\hline 3 & $\begin{array}{l}\text { Производственно- } \\
\text { технологическая инфраструктура }\end{array}$ & 35 & 33 \\
\hline 4 & Финансовая инфраструктура & 7 & 12 \\
\hline
\end{tabular}

Из таблицы 1 следует, что финансовая инфраструктура Уральского ФО по сравнению с Приволжским ФО значительно развита и числовое значение показателя большего аналогичного в 1,7 раза. Столь существенная разница в развитии финансовой инфраструктуры (банки, страховые и инвестиционные компании и др.) округов в дальнейшем может повлечь существенную разницу в социально-экономическом развитии территорий внутри округов и самих округов в целом.

Социально-экономическому росту Пермского края способствует наличие целого ряда центров экономического роста - городов и районов с экспортными отраслями. Однако, край имеет существенные социально-экономические проблемы: сильные внутрирегиональные различия экономики и рынков труда, типичные для индустриальных регионов с преобладанием монофункциональных городов, имеющих отрасли разной конкурентоспособности; депрессивность городов и районов угольной промышленности, сильнейшее неравенство по доходу; низкая продолжительность жизни из-за преобладания тяжелого физического труда, экологических проблем и распространенности асоциального поведения; пониженная обеспеченность и доступность основных социальных услуг за пределами областного центра, что подтверждает особую актуальность выбранной темы диссертационного исследования. Действительно, крайне обострены противоречия между экономически успешным и в целом социально благополучным инновационным технологическим лидером с экономически развитым округом, краем, центром и многочисленными моногородами округа с неконкурентоспособными предприятиями различных отраслей, с неразвитой сетью социальных услуг, с демографическими, миграционными проблемами и неразвитыми рынками труда и неразвитой или деградирующей инфраструктурой интеграции знаний, производственной-технологической и финансовой инфраструктурой.

Как уже отмечалось выше, Приволжский Федеральный округ по критерию «абсолютное значение числа моногородов» является самым проблемным. Согласно другим критериям ранжирования, самая большая доля монопрофильных 
городов приходится на Уральский ФО $(0,52)$, а монопрофильных поселков городского типа - в Дальневосточном ФО. Наибольшее число жителей монопрофильных населенных пунктов - в Уральском ФО (4,5 млн. чел.), самая высокая доля населения в монопрофильных городах - в Сибирском ФО (61\%). Общие проблемы моногородов РФ заключаются, в первую очередь, в:

- износе основных фондов градообразующих предприятий,

- использовании старых технологии в производстве,

- удаленность моногородов от экономически развитых центров,

- неразвитость транспортной инфраструктуры,

- зависимость бюджетов муниципалитетов от налоговых поступлений градообразующих предприятий.

В особый класс общих проблем моногородов выделяется отрицательная динамика социально-экономических процессов - центральное противоречие экономически успешного округа, края (области), центра и экономически и социально проблемного моногорода.

В начале кризисного периода (конец 2008 г. - начало 2009 г.), снижение спроса на продукцию предприятий моногородов резко ухудшило экономическое положение самих градообразующих предприятий, населения городов и привело к увольнениям рабочих и сотрудников, сокращению рабочей недели, уменьшению заработной платы.

Решение проблем монопрофильных городов связано с их выходом из условий монопрофильности, что предполагает диверсификацию производства градообразующего предприятия, создание новых инновационных производств на территории или вблизи моногорода, проведение политики повышения конкурентоспособности предприятий моногорода. Экономические эффекты приведут к социальным последствиям: будут созданы новые рабочие места, увеличится занятость и доходы местного населения, повысится спрос на товары и услуги, возрастет товарооборот, получит развитие малый и средний бизнес, увеличатся поступления налогов в бюджет, снизится социальная напряженность.

Все это станет следствием развития новых конкурентоспособных предприятий, фирм в случае правильно выбранных направлений развития моногорода с учетом воздействия внутренней и внешней среды, что относится к вопросам стратегического планирования развития моногорода, региона, страны в целом, перспектив развития отраслей в условиях инновационной экономики.

В случае отсутствия ясной и четкой стратегии развития региона, моногороду сложно определить направления своего развития, он должен быть учтен в плане экономического развития более крупного региона, как субъект хозяйственной деятельности, производитель и потребитель товаров и услуг. В условиях рыночной экономики и острой конкуренции регионов и городов за ресурсы и потребителя, необходимо выявить точки роста (конкурентоспособности) и только затем создавать условия формирования, создания и развития предприятий перспективной отрасли. В противном случае следует сосредоточить свое внимание на действующем предприятии, как создающим предложение на рынке труда моногорода и имеющим перспективы развития, при условии модерни- 
зации производства и получения доступа на рынки сбыта его конкурентоспособной продукции.

В научной литературе обсуждаются различные пути дальнейшего развития российских моногородов. Среди них указываются: диверсификация экономики моногорода, реструктуризация градообразующего предприятия, его модернизация, полная смена направленности экономики моногорода через строительство и развитие предприятий других отраслей, переезд жителей в другой город (региОН).

\section{ВЫВОДЫ}

Достижение целей, выдвинутых в многочисленных программах развития российских моногородов, реализация их конкретных мероприятий связаны с успешностью трех основных направлений управления социальноэкономическими процессами, разделяемых по критерию функционального и целевого назначения. Первое нацелено на процессы, обусловленные фазами экономического цикла или необходимостью проведения достаточно масштабных экономических преобразований, а также их социальные последствия. В рамках этого направления государство, главный субъект управления в обществе, воздействует на социально-экономические процессы посредством осуществления мер антикризисного регулирования: предотвращение и ликвидация неплатежеспособности и банкротства, преодоление спада производства и достижение стабилизации с последующим наращиванием объема конкурентоспособной продукции и услуг, снижение безработицы, рост доходов населения.

Второе направление - управление общеэкономическими процессами в целом, обусловленное необходимостью оптимального использования таких эффективных регуляторов экономики, как ценообразование, налогообложение, кредитование и инвестиции в развитие предпринимательства и технологической базы производителей.

Третье направление управления носит обеспечивающий характер и охватывает процессы, связанные с улучшением использования имеющихся природных, материальных, трудовых и финансовых ресурсов.

Позитивным фактором развития моногородов следует считать проводящуюся реконструкцию градообразующих предприятий с выходом новой продукции на внешний рынок, планы развития транспортной инфраструктуры, инфраструктуры сервиса. Дополнительным позитивным фактором следует признать расширение лизинга современного оборудования, развитие кредитного сотрудничества градообразующего предприятия с банками регионов, профессиональное сопровождение инвестиционных проектов. Согласно стратегии развития металлургической промышленности России на период до 2020 г., предусматривается реконструкция и модернизация производств на предприятиях металлургических комплексов целого ряда федеральных округов, в целях обеспечения выпуска конкурентоспособной продукции с высокой долей добавленной стоимости. Данный фактор следует считать как дополнительный пози- 
тивный при прогнозировании дальнейшего развития градообразующих предприятий металлургической отрасли и самих моногородов.

Существенными угрозами и сложностями в развитии металлургической отрасли в целом, и как следствия - металлургическим предприятиям, являются возрастающий дефицит высококвалифицированных рабочих кадров, исчерпание ряда месторождений, отставание геолого-разведочных работ, возрастание экологических требований, усложнение ситуации с энергообеспечением и усиливающаяся конкуренция со стороны новых индустриальных стран.

Как и в моногородах других федеральных округов, необходимы стратегические проекты по реконструкции металлургических предприятий, горнообогатительных комбинатов, осуществление добычи и обогащения черных металлов, прокатного производства. Такие проекты, например, в металлургическом комплексе Северо-Западного ФО будут связаны с реконструкцией металлургических предприятий в городах Череповец, Волхов, Кандалакша, Надвоицы, Мончегорск, Никель и С-Петербург, горно-обогатительного комбината в г. Костомукша. Предусматривается добыча и обогащение руд черных и цветных металлов в Мурманской области, прокатное производство - в С-Петербурге, добыча алмазов - в Архангельской области.

\section{ЛИТЕРАТУРА}

1. Стратегия социально-экономического развития северо-западного федерального округа на период до 2020 года. Обзор металлургической отрасли России (2010-2011гг.) Электронный pecypc http://www.ocenkavip.ru/content/obzor-metallurgicheskoi-otrasli-rossii-2010-2011gg Дата обращения 26.10.12

2. Доклад о результатах и основных направлениях деятельности министерства промышленности и торговли российской федерации на 2011-2013 годы; Стратегия развития металлургической промышленности России на период до 2020 года. Электронный ресурс www. rusmet.ru

3. Материалы промышленной выставки Иннопром 2010; Екатеринбург. Электронный ресурс

4. Исследовании IRP GROUP- 2010, электронный ресурс www.irpgroup.ru,

5. Горин, Н.И. Историческая динамика городского расселения в России/ Н.И. Горин // Социально-экономические аспекты управления регионами в посткризисный период / Тематический сборник научных трудов. - Курган: КФ АТиСО, 2009. - 155 с.

6. Любовный, В.Я. Монопрофильные города в условиях кризиса: состояние, проблемы, возможности реабилитации / В.Я. Любовный - М.: Институт макроэкономических исследований; Российская академия архитектуры и строительных наук, 2009. - 104 с.

1 Стратегия социально-экономического развития северо-западного федерального округа на период до 2020 года. Обзор металлургической отрасли Рос- 
сии (2010-2011гг.) Электронный ресурс http://www.ocenkavip.ru/content/obzormetallurgicheskoi-otrasli-rossii-2010-2011gg Дата обращения 26.10.12

2 Там же.

3 Доклад о результатах и основных направлениях деятельности министерства промышленности и торговли российской федерации на 2011-2013 годы; Стратегия развития металлургической промышленности России на период до 2020 года. Электронный ресурс www. rusmet.ru

4 Там же.

5 Материалы промышленной выставки Иннопром 2010; Екатеринбург. Электронный ресурс

6 Исследовании IRP GROUP- 2010, электронный ресурc www.irpgroup.ru, 7 Данные 2010 г. 